\title{
Understanding the Role of Intrinsic Disorder of Viral Proteins in the Oncogenicity of Different Types of HPV
}

\author{
Elvira Regina Tamarozzi and Silvana Giuliatti * \\ Department of Genetics, School of Medicine of Ribeirão Preto, University of São Paulo, Sao Paulo 14049-900, \\ Brazil; elvira@usp.br \\ * Correspondence: silvana@fmrp.usp.br; Tel.: +55-(16)-3315-4503
}

Received: 19 December 2017; Accepted: 7 January 2018; Published: 9 January 2018

\begin{abstract}
Intrinsic disorder is very important in the biological function of several proteins, and is directly linked to their foldability during interaction with their targets. There is a close relationship between the intrinsically disordered proteins and the process of carcinogenesis involving viral pathogens. Among these pathogens, we have highlighted the human papillomavirus (HPV) in this study. HPV is currently among the most common sexually transmitted infections, besides being the cause of several types of cancer. HPVs are divided into two groups, called high- and low-risk, based on their oncogenic potential. The high-risk HPV E6 protein has been the target of much research, in seeking treatments against HPV, due to its direct involvement in the process of cell cycle control. To understand the role of intrinsic disorder of the viral proteins in the oncogenic potential of different HPV types, the structural characteristics of intrinsically disordered regions of high and low-risk HPV E6 proteins were analyzed. In silico analyses of primary sequences, prediction of tertiary structures, and analyses of molecular dynamics allowed the observation of the behavior of such disordered regions in these proteins, thereby proving a direct relationship of structural variation with the degree of oncogenicity of HPVs. The results obtained may contribute to the development of new therapies, targeting the E6 oncoprotein, for the treatment of HPV-associated diseases.
\end{abstract}

Keywords: intrinsically disordered proteins; computational prediction; E6 protein; HPV; cancer

\section{Introduction}

The function of proteins is not solely linked to their rigid three-dimensional structure, as was thought less than three decades ago. Studies with physiologically unstructured, yet biologically active, proteins were conducted to challenge the concept based on the structure-function paradigm, according to which the function of a protein is exclusively determined by its rigid three-dimensional structure [1].

Several studies, conducted on these proteins lacking a defined structure, demonstrated that the intrinsic physiological disorder allows the protein to act like a ligand that folds, partially or totally, upon interaction with its targets [2]. These observations gave rise to the concept that partial or total intrinsic disorder, present in many proteins, might have biological significance. The way these proteins fold is part of its function, being an important factor in the interaction with its specific targets. Thus, the function of intrinsically disordered proteins is considered to be directly linked to their folding ability during their interaction with the targets $[3,4]$.

Since intrinsic disorder (ID) is essential for the biological function of various proteins, and might occur in varied environments, the amino acid sequences constituting such disordered regions are specifically determined by the characteristics of their local and global environment. Thus, based on the association of the heterogeneity of ID in proteins with several environmental factors, it is possible 
to assume that ID might occur in a specific way for each disordered protein (or family of disordered proteins) $[3,5]$.

Comprehensive analysis of several known proteomes has shown that viral proteins have a greater amount of ID compared to human proteins. The content of disordered regions in viral proteins is directly linked to the pathogenicity and oncogenicity of the virus [6]. The presence of large ID regions in viral proteins has several functional implications; some of these regions are indispensable for the functioning of these proteins, for example in the invasion of host cell pathways, as a means of adaptation, accommodation of the virus in hostile habitats, and also to help the virus in the proper management of its genetic material [5-7].

The impact of human papillomavirus (HPV) on health was the main motivation for the extensive study and documentation of its characteristic features. The HPVs have more than 150 different genotypes that were fully sequenced and numbered by their order of discovery $[8,9]$.

Currently, HPV is one of the most common sexually transmitted infections, besides being the cause of a series of neoplasms, including cervical, vulvar, vaginal, penile, anal, and head-and-neck cancers. In addition, it is a common cause of genital warts and recurrent respiratory papillomatosis that is somewhat uncommon, yet very severe and etiologically associated with HPV [8,10-12].

There are approximately 40 types of HPV that cause infections. The different types are divided into two groups namely High- and Low-Risk, based on their oncogenic potential. According to reports by the International Agency for Research on Cancer and the World Health Organization, HPVs of high oncogenic risk in humans are: types $16,18,31,33,35,39,45,51,52,56,58,59$, and 66 due to their high prevalence in different types of cancer samples [13,14]. HPV types 6, 11, 40, 42, 43, 44, and 54 are considered to be of low oncogenic risk, causing particularly benign lesions, such as genital warts, low-grade intraepithelial squamous lesions, and laryngeal papillomatosis [13-15].

The HPV viral genome encodes nonstructural proteins E1, E2, E3, E4, E5, E6, and E7, required for viral replication and transcription $[8,14]$. The E6 and E7 proteins are considered to be of high oncogenic risk because of their role in inhibiting cell differentiation. These proteins are associated with the modification of normal epithelial differentiation, blockade of apoptosis, DNA synthesis, and inhibition of cell cycle control $[8,16,17]$. Therefore, these proteins have been important molecular targets in the search for treatments against HPV.

Studies with E7 proteins from different HPV types have shown a relationship between the different patterns of intrinsic disorder and the degree of viral oncogenicity. E7 proteins from high-risk HPVs, type 16 and 18, show an increase in the size of intrinsically disordered regions relative to that in the low-risk HPV proteins [18]. Other studies propose that intrinsic disorder is relatively abundant even among several established cancer-related proteins $[19,20]$.

The study of intrinsic disorder and its impact on three-dimensional structures of E6 proteins of high and low-risk types of HPV can provide further information about the structural behavior and function of these proteins.

\section{Results}

\subsection{Analysis of Intrinsic Disorder}

Based on data published by the International Agency for Research on Cancer and the World Health Organization [13,14], 15 types of high-risk HPVs most frequently related to cancer, and 12 types of low-risk HPVs most frequently related to benign lesions, were chosen. A type of HPV, related to neither cancer nor benign lesions [13], was chosen as a control in the analyses (Table 1).

The primary sequences of high-risk, low-risk, and control HPV E6 proteins were obtained from the UniProt database (http:/ / www.uniprot.org/).

All sequences were analyzed individually and the results obtained were compared to each other.

Table 1 shows the number of disordered amino acids at the two termini and the overall percentage of intrinsic disorder of E6 proteins, analyzed by the PONDR-FIT software [21]. 
The N-terminal and C-terminal ends of the high-risk HPV E6 proteins were observed to have a higher number of disordered amino acids and a higher percentage of ID relative to the total length of the sequence when compared to those of the low-risk and control HPV E6 proteins.

Table 1. Number of disordered amino acids and general percentage of intrinsic disorder in E6 proteins.

\begin{tabular}{|c|c|c|c|c|c|}
\hline HPV Type & Classification & \#Residues & $\%$ ID & $\begin{array}{l}\text { Disordered Amino } \\
\text { Acids N-Terminal }\end{array}$ & $\begin{array}{l}\text { Disordered Amino } \\
\text { Acids C-Terminal }\end{array}$ \\
\hline HPV1A & Control & 140 & 8.6 & 6 & 6 \\
\hline HPV16 & High-Risk & 158 & 39.9 & 23 & 40 \\
\hline HPV18 & High-Risk & 158 & 27.2 & 14 & 29 \\
\hline HPV31 & High-Risk & 149 & 38.9 & 20 & 38 \\
\hline HPV33 & High-Risk & 149 & 35.6 & 16 & 37 \\
\hline HPV35 & High-Risk & 149 & 33.6 & 13 & 37 \\
\hline HPV39 & High-Risk & 158 & 31.6 & 8 & 42 \\
\hline HPV45 & High-Risk & 158 & 31.6 & 13 & 37 \\
\hline HPV51 & High-Risk & 151 & 33.1 & 18 & 32 \\
\hline HPV52 & High-Risk & 148 & 45.9 & 35 & 33 \\
\hline HPV56 & High-Risk & 155 & 27.1 & 20 & 22 \\
\hline HPV58 & High-Risk & 149 & 36.9 & 18 & 37 \\
\hline HPV59 & High-Risk & 160 & 25.6 & 15 & 26 \\
\hline HPV68 & High-Risk & 158 & 25.3 & 11 & 29 \\
\hline HPV73 & High-Risk & 148 & 14.2 & 14 & 7 \\
\hline HPV82 & High-Risk & 151 & 36.4 & 13 & 42 \\
\hline HPV6B & Low-Risk & 150 & 6.7 & 9 & 1 \\
\hline HPV11 & Low-Risk & 150 & 7.3 & 10 & 1 \\
\hline HPV40 & Low-Risk & 154 & 3.9 & 6 & 0 \\
\hline HPV42 & Low-Risk & 150 & 11.3 & 10 & 7 \\
\hline HPV43 & Low-Risk & 155 & 11.0 & 7 & 10 \\
\hline HPV44 & Low-Risk & 150 & 7.3 & 11 & 0 \\
\hline HPV53 & Low-Risk & 154 & 14.3 & 20 & 2 \\
\hline HPV54 & Low-Risk & 144 & 13.9 & 12 & 8 \\
\hline HPV61 & Low-Risk & 146 & 4.8 & 3 & 4 \\
\hline HPV66 & Low-Risk & 155 & 10.3 & 11 & 5 \\
\hline HPV72 & Low-Risk & 148 & 4.7 & 6 & 1 \\
\hline HPV81 & Low-Risk & 154 & 7.8 & 10 & 2 \\
\hline
\end{tabular}

\#Residues number refers to the number of amino acid residues.

Analysis of ID distribution shows that the disordered amino acids are predominantly located at the C-terminus of the high-risk HPV E6 proteins, which has a higher amount of ID compared to the low-risk HPV E6. The general comparison between the disordered residues of high and low-risk HPV E6, together with those of the control, reveals the difference in the proportion of ID between the proteins analyzed (Figure 1).

These results show that high-risk HPV E6 proteins present a greater amount of disordered amino acids at their N- and C-termini, suggesting the amount of ID as a possible factor causing the increased oncogenicity related to E6 proteins. Nominé et al. [22] showed that the E6 proteins of various types of HPV present a great variability in the length and sequence of the $\mathrm{N}$-terminal and C-terminal segments. Combining the sequence variability, previously described, with the N-terminal and C-terminal ID distribution pattern found in the present study, it is possible to infer that this combination is one of the determining factors for the varying degrees of oncogenicity of E6 proteins.

To understand the impact of ID on proteins better, it is necessary to analyze the tertiary structure of the regions corresponding to the disordered amino acids, especially at the termini. Till date, the vast majority of the three-dimensional structures of the known E6 proteins are not completely resolved, especially the terminal regions that are still incomplete $[23,24]$. Therefore, complete tertiary structures of the E6 proteins of high-risk HPV16 and HPV18, low-risk HPV6B and HPV11, and HPV1A control were modeled, so that the ID present at the termini could be analyzed in full. 


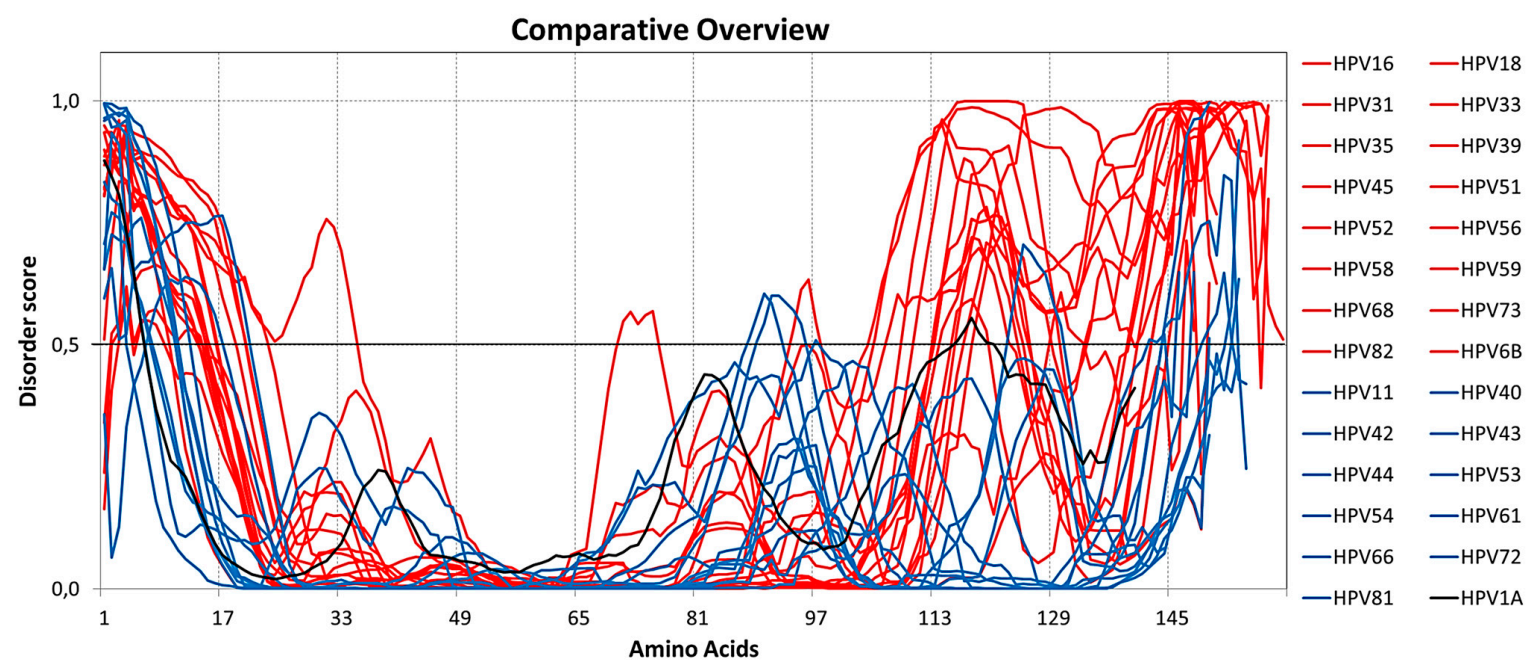

Figure 1. Intrinsic disorder analysis of E6 proteins of high and low-risk human papillomavirus (HPVs), oncogenic and control. The dashed lines at 0.5 of $y$-axis are threshold lines for disordered/structured residues. Residues with a score above this line are predicted disordered, and residues with a score below 0.5 are predicted to be ordered. Intrinsic disorder of HPV E6 proteins of high-risk (red), low-risk (blue), and control (black) are shown.

\subsection{Molecular Modeling of E6}

Figure 2A shows the complete three-dimensional structures of E6 proteins of the high-risk types HPV16 and HPV18, low-risk types HPV6B and HPV11, and of HPV1A control (available in supplementary material). Alignment of the structures showed that the major differences are located at the $\mathrm{N}$-terminal and C-terminal ends of the proteins (Figure 2B). The differences observed at both ends of the modeled E6 proteins correspond to the variations found in the length and sequence of these proteins.

\subsection{Simulation of Molecular Dynamics for RMSF Analysis}

The root mean square fluctuations (RMSF) values for the coordinates of the $\mathrm{C} \alpha$ atoms in the protein structure were obtained over the simulation time using their initial structure as reference to identify the amino acids that provide variable protein characteristics. The results of the RMSF analysis showed that a large number of structural variation occurs in the $\mathrm{N}$ - and C-termini of all the E6 proteins modeled. However, the C-terminus of the E6 proteins of the high-risk types 16 and 18 presented greater structural variation in relation to the other E6 proteins (Figure 3), which is consistent with the results obtained using the PONDR-FIT software that showed the intrinsic disorder at the two termini of all proteins analyzed. 

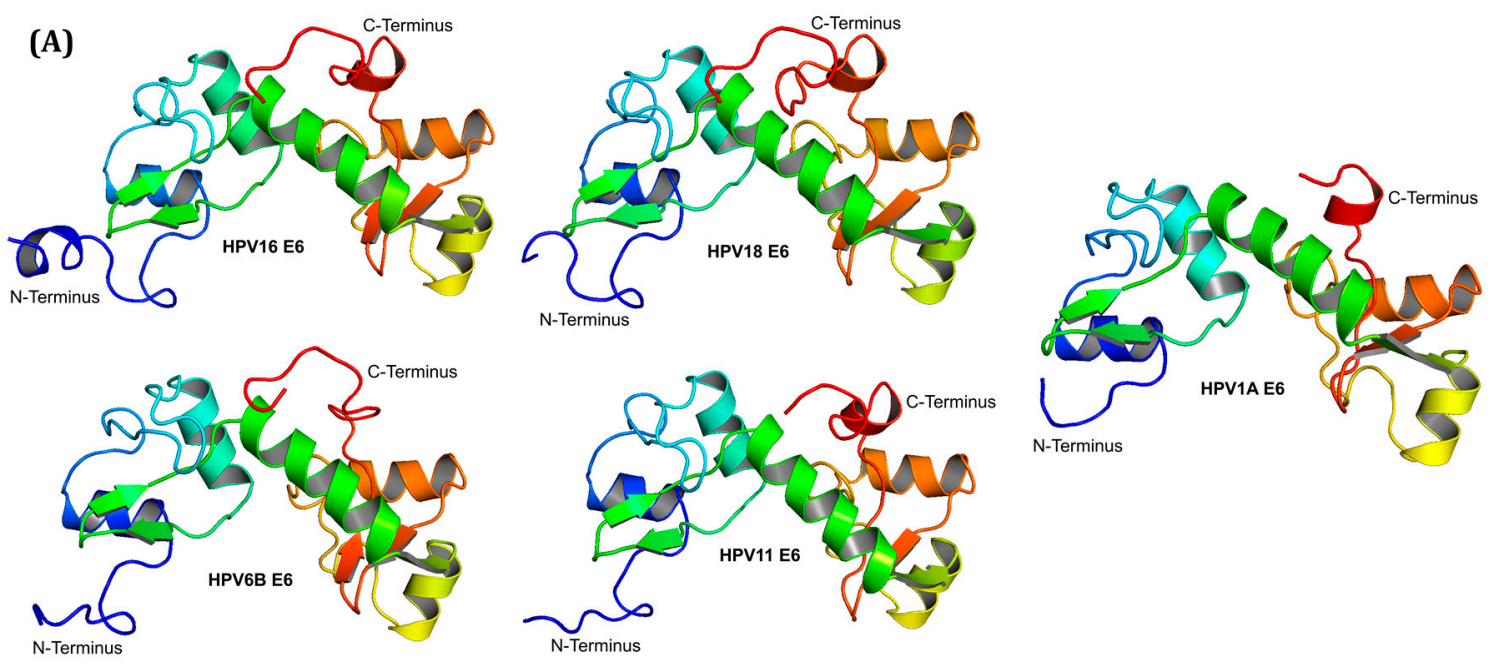

(B)

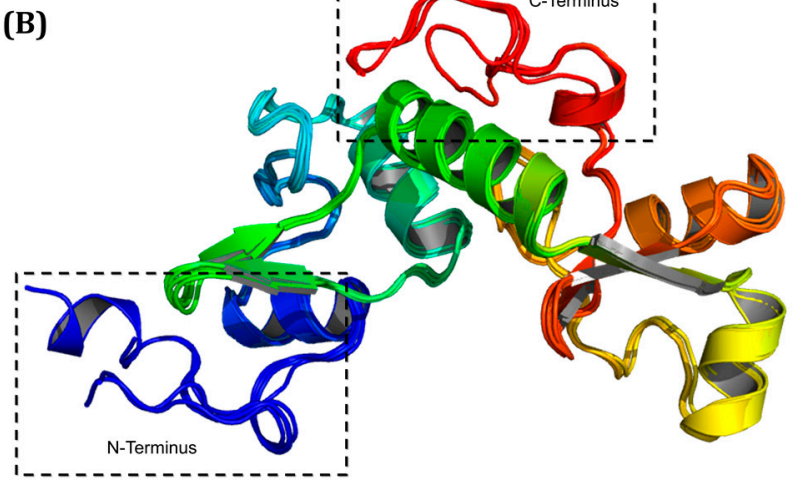

Figure 2. Representation of the three-dimensional structures of E6 proteins. (A) Complete structures of the E6 proteins of the HPV type 16 and 18 of high-risk, types $6 \mathrm{~B}$ and 11 of low-risk, and type $1 \mathrm{~A}$ control; (B) Alignment of the three-dimensional structures of HPV16, HPV18, HPV6B, HPV11, and HPV1A E6 proteins, clearly showing that the major structural differences are localized at the N-terminal and C-terminal ends (black dotted rectangles).

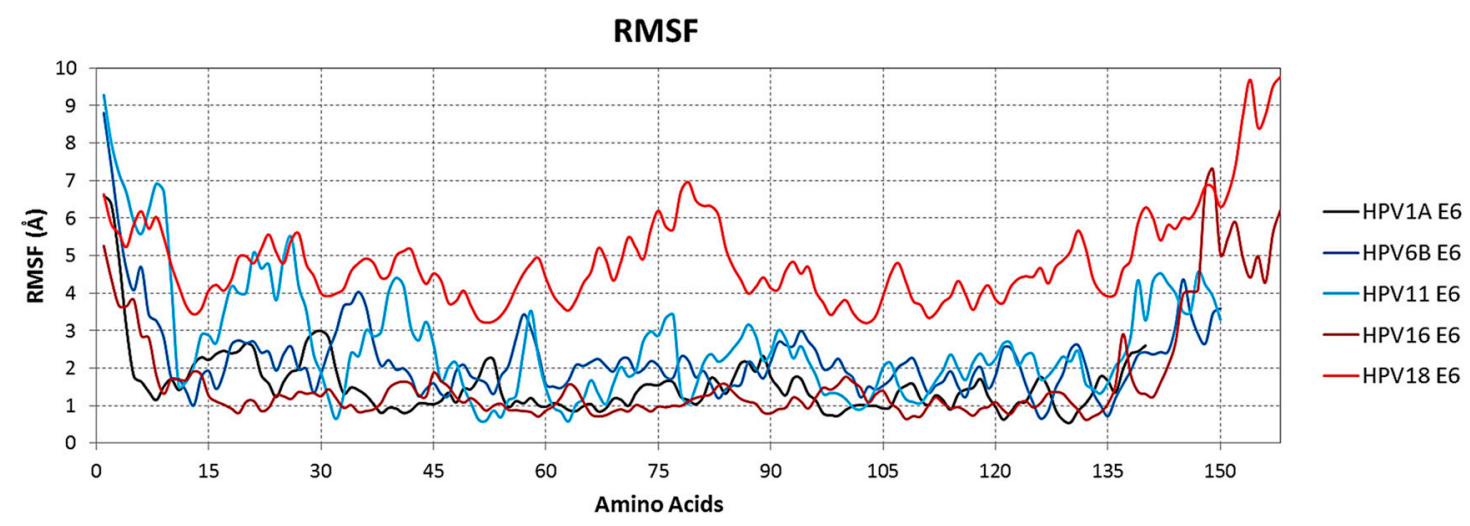

Figure 3. Structural variation of the disordered regions at the $\mathrm{N}$ - and C-termini of the proteins analyzed. Root mean square fluctuations (RMSF) values of $\mathrm{C} \alpha$ atom coordinates during the simulation have been plotted to show the structural variation of the N- and C-termini of E6 proteins from HPV16, HPV18, HPV6B, HPV11, and HPV1A. It is observed that high-risk HPVs present greater structural variation at the C-terminal end. All graphs were generated using the Gnuplot 4.6 software [25]. 
For a more detailed comparison of the $\mathrm{N}$ - and C-terminal intrinsic disorder between the high- and low-risk E6, the proteins from high-risk HPV type 16 and 18 were chosen because of their direct link to cervical cancer $[23,26]$, E6 of low-risk types $6 \mathrm{~B}$ and 11 were chosen because of their high prevalence in benign lesions related to HPV [26], and E6 of type 1A was chosen due to its lack of relation with either cancer or benign lesions [13].

Comparison of the two high-risk E6 proteins (HPV16 and HPV18) with the two low-risk E6 proteins (HPV6B and HPV11) shows a large difference in the amount of ID at the two termini, with E6 of HPV16 and HPV18 presenting 39.9\% and 27.2\% of disordered amino acids respectively, E6 of HPV6B and HPV11 presenting $6.7 \%$ and $7.3 \%$, respectively and E6 of HPV1A presenting $8.6 \%$, thereby showing that the amount of ID is significantly higher in both E6 termini of HPV16 and HPV18 (Figure 4).

Alignment of the three-dimensional structures, obtained during molecular dynamics simulation, was done using PyMOL 2.0 software [27]. Four conformations of each E6 protein of HPV16, HPV18, HPV6B, HPV11, and HPV1A, corresponding to times 0, 10, 30, and 40 ns (Figure 5) were aligned. As expected, the $\mathrm{N}$ - and $\mathrm{C}$-terminal regions, upon visual inspection, were found to be structurally most variable.

The mean of structural variation, calculated based on the distances of the conformations at 0,10 , 30, and $40 \mathrm{~ns}$, using the first amino acid of the N-terminal and the last amino acid of C-terminal end of E6 from HPV1A, HPV6B, HPV11, HPV16, and HPV18 was $8.63 \AA, 24.53 \AA, 19.03 \AA, 17.33 \AA$, and $14.47 \AA$, respectively, at the N-terminal and, $6.13 \AA, 6.90 \AA, 5.67 \AA, 21.23 \AA$, and $16.43 \AA$, respectively, at the C-terminal end.

The structure of the non-cancer-related HPV1A (control) E6 was the only one that showed lower structural variation at both its termini. The low-risk HPV6B and HPV11 E6 structures showed an increase in the structural variation at the termini compared to that in the control E6, primarily in the N-terminus that showed greater variation even when compared to the high-risk HPV16 and HPV18 E6. The structures of high-risk HPV16 and HPV18 E6 presented structural variation in both termini, though to a greater extent in the C-terminus compared to the other proteins. Despite the large structural variation of both termini of the E6 proteins analyzed, the central regions of the structures were observed to have little variation relative to the termini (Figure 5).

\section{Comparative ID}

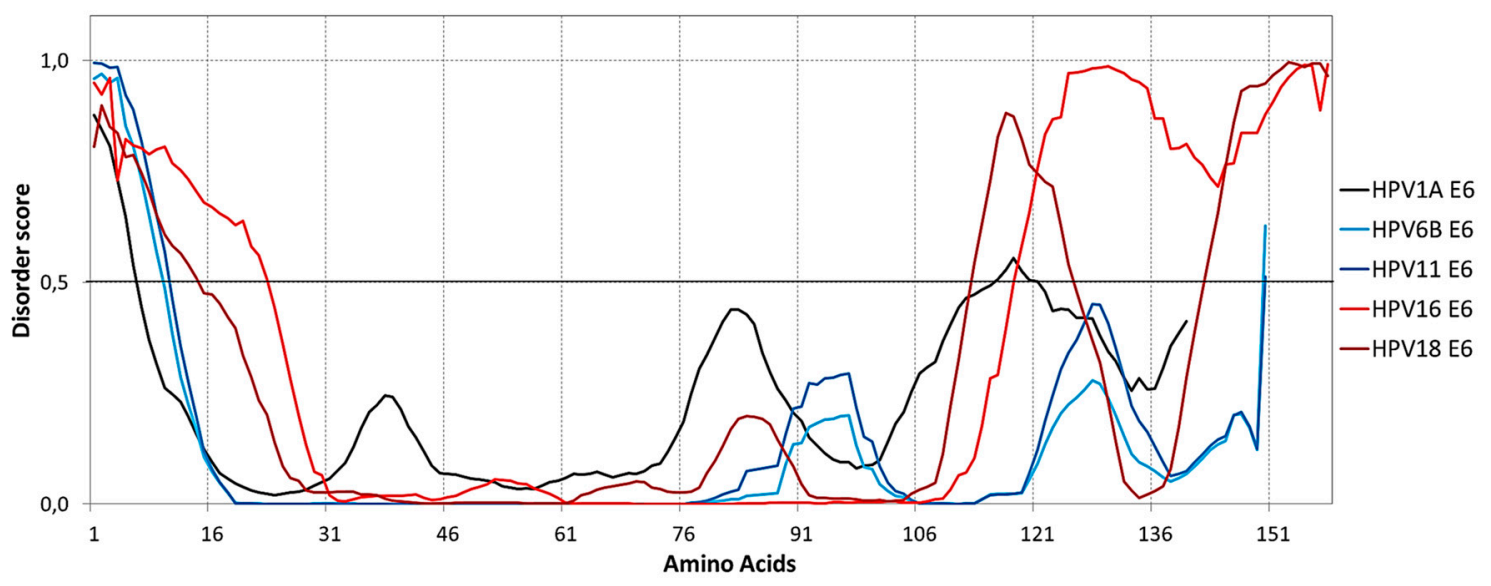

Figure 4. Comparison of intrinsic disorder between E6 of HPV16 and HPV18 (high-risk), HPV6B and HPV11 (low-risk), and HPV1A (control). High-risk HPV16 and HPV18 E6 proteins have considerably longer regions of intrinsic disorder at both ends, especially at the C-terminus. The dashed lines at 0.5 of $y$-axis are threshold lines for disordered/structured residues. Residues with a score above this line are predicted disordered, and residues with a score below 0.5 are predicted to be ordered. These results were obtained using the PONDR-FIT tools [21]. 

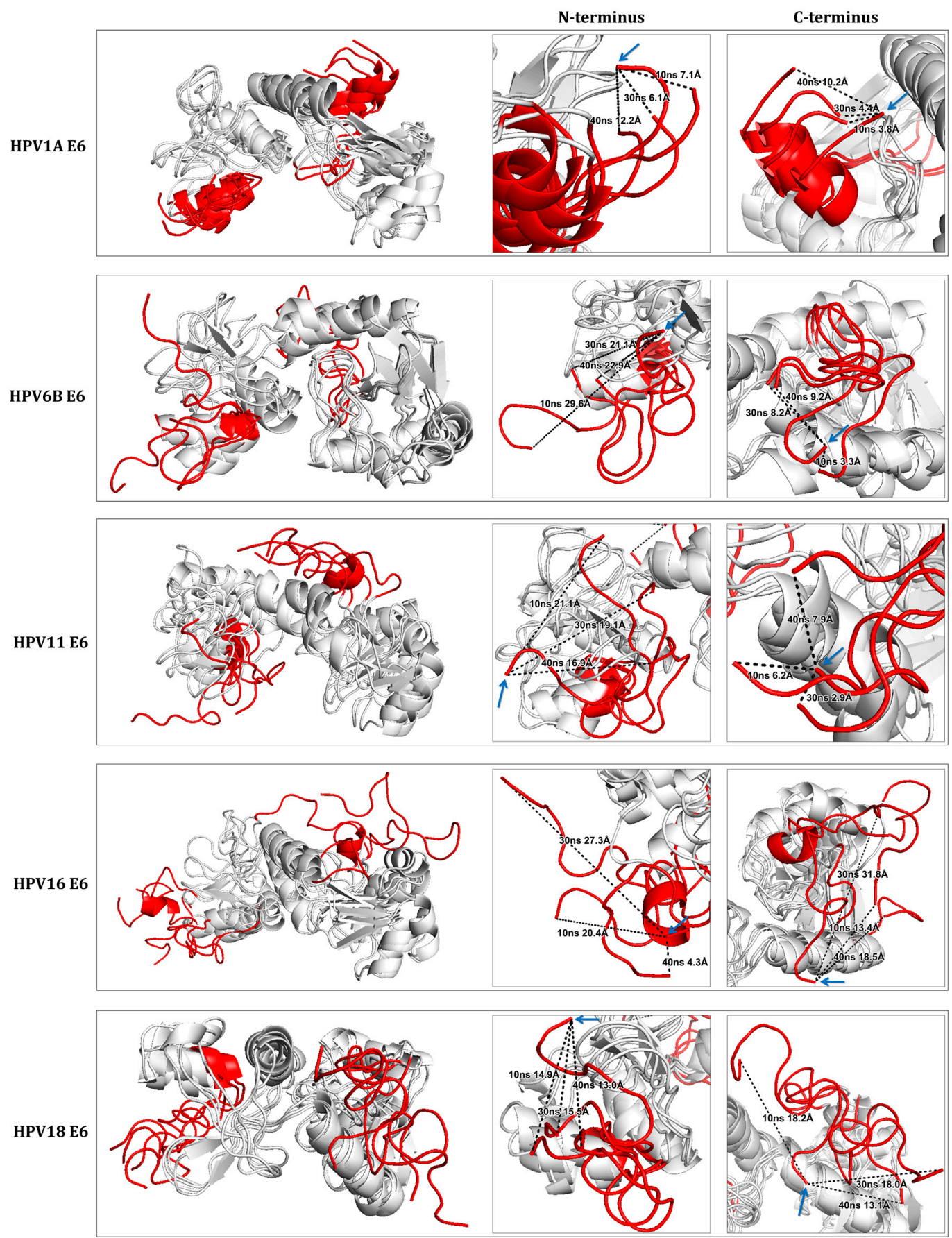

Figure 5. Comparison between the different structural conformations of E6 proteins from HPV16, HPV18, HPV6B, HPV11, and HPV1A by molecular dynamics simulation. The N- and C-termini of the structures are highlighted in red and the central region between the terminals is shown in gray. The panels, next to the aligned structures, highlight the two termini with the black dotted lines showing the distance of the variation of the same amino acids at times 0 (indicated by the blue arrow), 10, 30, and $40 \mathrm{~ns}$. It is observed that the structural variation occurs mainly in the terminal regions of all the structures. Distances were measured using PyMOL 2.0 software [27]. Dotted line: the distance of the variation of the same amino acids.

\subsection{Analysis of Electrostatic Potential and Hydrophobicity Profile}

The distribution of electrostatic potential and surface hydrophobicity of the E6 proteins were obtained through the ChimeraX software [28]. 
For visual analysis, the structures were all equally positioned, with the C-terminus at the left and $\mathrm{N}$-terminus at the right end of all the images contained in Figure 6.
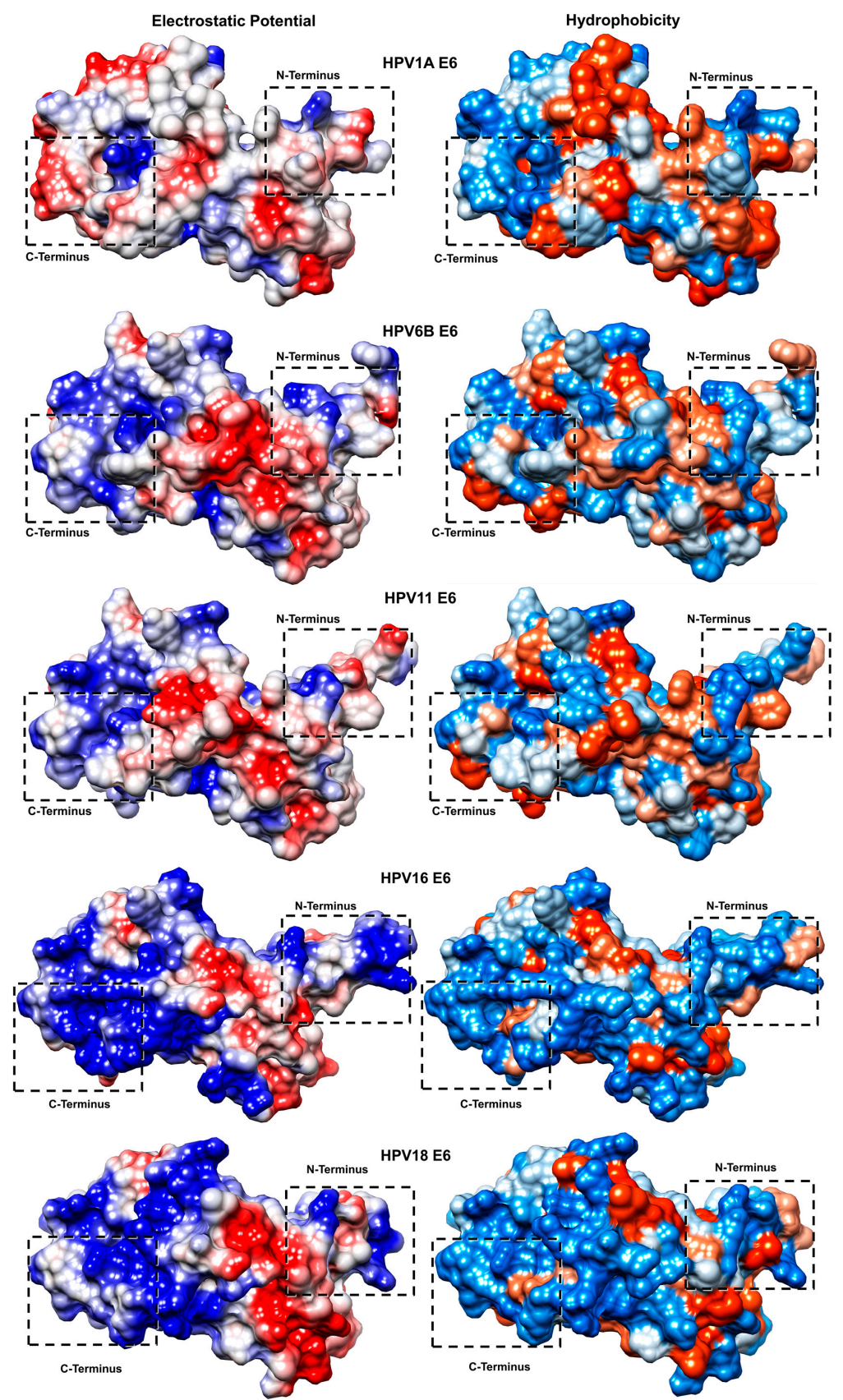

Figure 6. Distribution of electrostatic potential and surface hydrophobicity. The electrostatic potential distribution is shown in blue in the positively charged regions, red in the negatively charged regions, and white in the neutral regions. The hydrophobicity distribution on the protein surfaces is shown in blue for hydrophilic regions, orange for hydrophobic regions, and blank for neutral regions. The rectangles dotted in black show the regions corresponding to the $\mathrm{N}$ - and C-terminal surfaces. HPV1A, HPV6B, and HPV11 (control and low-risk) oncogenic E6 proteins have a greater proportion of neutral and hydrophobic electrostatic characteristics in the regions corresponding to the $\mathrm{N}$ - and C-terminal surfaces. The distribution of electrostatic potential and hydrophobicity of the surfaces of highly oncogenic HPV16 and HPV18 E6 proteins present predominantly positive and hydrophilic characteristics at the termini of both structures. The rectangles dotted in black show the regions corresponding to the $\mathrm{N}$ - and $\mathrm{C}$-terminal surfaces. 
Surface analyses showed a similar pattern in the distribution of electrostatic potential and hydrophobicity between the high-risk HPV16 and HPV18 E6 structures. The same was true for the low-risk HPV6B and HPV11 E6 structures that share a pattern similar to each other as well as to that of HPV1A E6 (control) (Figure 6).

Positively charged and hydrophilic regions were predominant at the C-terminus of all the structures, with the largest regions observed in high-risk HPV16 and HPV18 E6 proteins. The electrostatic surface of the low-risk HPV6 and HPV11 E6 and HPV1A E6 structures showed a predominance of neutral and hydrophobic regions compared to that in the high-risk E6 structures.

The propensity of intrinsic disorder in proteins is related to the physicochemical characteristics of the amino acids that compose them. Studies have shown that hydrophobic residues are rarely encountered in most regions of intrinsic disorder, whereas hydrophilic and positively charged residues are found in abundance [29,30]. These specific characteristics of predominance of positively charged and hydrophilic regions at the $\mathrm{N}$ - and C-termini were found to correspond to the higher ID regions of the high-risk oncogenic E6 proteins.

\section{Discussion}

The presence of intrinsically disordered regions in proteins is directly related to signaling and regulation of the cell cycle [3]. In previous studies, intrinsic disorder has been linked to different types of cancer-related proteins [18,20], such as the p53 protein [31], P57 kip2 [32], Bcl-x L and Bcl-2 [33], C-Fos [34], TC-1 [35], and EWS [36].

Viruses are obligate intracellular parasites, because their genomes are not large enough to encode all the functions necessary to reproduce their progeny independently. Thus, viruses are categorically dependent on host-cell functions [37]. ID, commonly found in viral proteins, allows plasticity in its interaction with different targets and also promotes its adaptation to various environmental conditions [38].

ID also confers high mutation rates on viral proteins, giving rise to new viral types, subtypes, and variants [37,38]. A recent study has shown that viral variants of the HPV16 E6 protein show conservation of the disordered regions, implicating a significant function of these proteins (results not yet published by our group).

To date, there are several partial structures of the E6 proteins that has been solved experimentally, the structure of HPV16 E6 is the best studied and described [23,24]. The complete structural determination of $\mathrm{E} 6$ proteins of the high-risk types 16 and 18, low-risk types $6 \mathrm{~B}$ and 11, and control $1 \mathrm{~A}$, in this study, will help to analyze the structural behavior of the intrinsically disordered regions along the protein length, as well as to understand the characteristics of electrostatic potential and hydrophobicity profile of the surface of these proteins.

RMSF analysis showed that, during the molecular dynamics simulation, both ends, mainly the C-terminus of the high-risk E6 proteins, present greater structural variation, corroborating the results presented by the PONDR-FIT tool. The analyses of electrostatic potential and hydrophobicity profile also confirmed the prediction of ID and structural variability, showing that the surface regions at the termini present prominent positively charged and hydrophilic characteristics, corresponding to the established physicochemical characteristics of regions with IDs, already described in other proteins $[29,30]$.

Although the best-described function of E6 is to induce degradation of p53, several studies have indicated E6 proteins to have many other molecular targets. One of the major binding sites described for E6 protein is located in its C-terminal domain, the PDZ (postsynaptic density 95/disc large/zonula occludens-1) binding motif [24,39]. The PDZ binding motif is specifically conserved among the high-risk HPV E6 proteins and is essential for recognizing, binding, and enhancing the degradation of various PDZ domain-containing proteins, such as discs large homolog 1 (DLG1), discs large homolog 4 (DLG4), SCRIB (scribble homolog), membrane-associated guanylate kinase inverted 1 (MAGI1), and tyrosine-protein phosphatase non-receptor type 13 (PTPN13) [39,40]. Several 
studies suggest that the motif of binding to the PDZ domain is particularly important for cell transformation and tumorigenesis [39,41]. The recent study by Yoshimatsu et al. [39] shows that the PDZ domain-binding motif located at the C-terminus of HPV type 16 E6 is critical to induce proliferation, anchorage-independent growth, and tumorigenic cellular potential of the virus. These data strengthen the results obtained in the present study, where the highest proportion of intrinsic disorder and structural variation was observed in the C-terminus of the high-risk E6 proteins, indicating that ID can confer a better recognition and interaction capacity with PDZ domains of their molecular targets, suppressing their functions more efficiently, and increasing the tumorigenesis caused by the virus.

Corroborated by the studies conducted by Uversky et al. [19] and Nicolau and Giuliatti [18], where differences in the content of ID were observed in E6 and E7 oncoproteins of high-risk HPV, the results obtained in our study reveal that, the N-terminal and C-terminal amino acids of the high and low-risk E6 proteins are responsible for causing variation in the degree of ID and, consequently, explain the variation of structure and dynamics between the E6 structures. These differences in the structures may implicate a specific behavior of each E6, when complexed with its target proteins, imparting a possible advantage over molecular interaction.

The variation in the amount of ID and structural characteristics might indicate that these factors are responsible for the differences in degree of oncogenicity and viral persistence of the E6 proteins. These data need to be confirmed further using the E6 proteins of high and low-risk HPV, and also in complex with their main targets, such as p53, E6AP, and other possible molecular targets. The acquired knowledge would contribute to studies that seek efficient prophylactic methods and drug therapies against HPV and related pathologies.

\section{Materials and Methods}

\subsection{Obtaining the Primary Sequences}

The types of high and low-risk HPV, used in this study, were chosen based on data published by the International Agency for Research on Cancer and the World Health Organization [13,14].

The primary sequences of the high and low-risk HPV E6 proteins are presented in Table 2. These data were obtained from the UniProt Database (http:/ / www.uniprot.org/).

Table 2. Primary sequences of high and low-risk HPV E6 proteins.

\begin{tabular}{cccc}
\hline HPV Type & Classification & ID UniProtKB & \#Residues \\
\hline HPV1A & Control & P06929 & 140 \\
HPV16 & High-Risk & P03126 & 158 \\
HPV18 & High-Risk & P06463 & 158 \\
HPV31 & High-Risk & P17386 & 149 \\
HPV33 & High-Risk & P06427 & 149 \\
HPV35 & High-Risk & P27228 & 149 \\
HPV39 & High-Risk & P24835 & 158 \\
HPV45 & High-Risk & P21735 & 158 \\
HPV51 & High-Risk & P26554 & 151 \\
HPV52 & High-Risk & P36814 & 148 \\
HPV56 & High-Risk & P24836 & 155 \\
HPV58 & High-Risk & P26555 & 149 \\
HPV59 & High-Risk & B9UPD9 & 160 \\
HPV68 & High-Risk & Q7KYK8 & 158 \\
HPV73 & High-Risk & Q82005 & 148 \\
HPV82 & High-Risk & Q9IR59 & 151 \\
HPV6B & Low-Risk & P06462 & 150 \\
HPV11 & Low-Risk & P04019 & 150 \\
\hline
\end{tabular}


Table 2. Cont.

\begin{tabular}{cccc}
\hline HPV Type & Classification & ID UniProtKB & \#Residues \\
\hline HPV40 & Low-Risk & P36812 & 154 \\
HPV42 & Low-Risk & P27229 & 150 \\
HPV43 & Low-Risk & P19709 & 155 \\
HPV44 & Low-Risk & P19710 & 150 \\
HPV53 & Low-Risk & Q17UC4 & 154 \\
HPV54 & Low-Risk & Q81018 & 144 \\
HPV61 & Low-Risk & Q80948 & 146 \\
HPV66 & Low-Risk & Q80955 & 155 \\
HPV72 & Low-Risk & Q81997 & 148 \\
HPV81 & Low-Risk & Q705E9 & 154 \\
\hline
\end{tabular}

\#Residues number refers to the number of amino acid residues.

\subsection{Prediction and Analysis of Intrinsic Disorder}

Currently, there are several computational tools for predicting intrinsic disorder. Based on the different methodologies available, the PONDR-FIT software [21] was used to predict regions of intrinsic disorder in E6 proteins of different HPV types.

PONDR-FIT employs the unification of the methodologies of six predictors namely, PONDR ${ }^{\circledR}$ VLXT, PONDR ${ }^{\circledR}$ VL3, PONDR ${ }^{\circledR}$ VSL2, IUPred, FoldIndex, and TopIDP. The output data are composed of a table that individually scores each of the amino acids in the sequence, indicating the probability of each residue being structured or disordered. While the values less than 0.49 represent structured amino acids, those greater than 0.5 represent the intrinsically disordered amino acids. The PONDR-FIT consensus predictor analyzes each amino acid throughout the sequence, taking into account the characteristics of the neighboring amino acids. The prediction results of the six tools are weighed in a sliding window of 21 residues, centered on the residue being analyzed [21,42].

\subsection{Macromolecular Modeling and Ab Initio Modeling}

Primary structure of the HPV16 E6 protein (P03126) was obtained from the public database UniProt (http://www.uniprot.org). The structure of HPV16 E6 oncoprotein, obtained by X-ray crystallography, in complex with the LXXLL peptide of the E6AP protein (PDB ID: 4GIZ), was used as a template structure [23].

The structure of HPV16 E6 was partly modeled by homology modeling. For this, the server @TOME-2 [43], which uses the computer program MODELLER [44], was used. Five modeled structures were generated and evaluated by ERRAT [45], PROCHECK [46], and visual inspection.

Residues 1-8 and 151-158, in the N- and C-terminal regions of HPV16, respectively, were absent in the template structure and were modeled ab initio. The Cyclic Coordinate Descent (CCD) module [47], implemented in the computer program Rosetta 3.1 [48], was used to generate 1000 templates from HPV16 E6, which were ranked by a score function using the computer programs ModFOLD [49] and QMEAN [50]. The top 20 modeled structures (the 10 highest scores sorted by each scoring function without redundancy) were evaluated by MQAPs and visual inspection. In order to obtain high-quality structures, the side chains (rotamers) of the final structure, were re-modeled using SCWRL4 [51].

The structure of the fully modeled HPV16 E6 protein was used as a template for the homology modeling of the E6 proteins from HPV1A, HPV6B, HPV11, and HPV18. Using the computer program MODELLER, five structures for each target were generated.

The best structure was selected and analyzed by visual inspection and MQAPs. The side chain modeling was performed by the computer program SCWRL4. 


\subsection{Analysis of Electrostatic Potential and Hydrophobicity Profile}

For prediction of the electrostatic potential distribution and hydrophobicity profile of the protein surface, UCSF ChimeraX software [28] was used.

UCSF ChimeraX calculates the electrostatic surface potential of proteins according to Coulomb's Law. For prediction of the hydrophobicity profile, it attributes a property called kdHydrophobicity to the amino acids individually; its values vary according to the hydrophobicity scale of Kyte and Doolittle [52].

\subsection{Simulation of Molecular Dynamics}

For molecular dynamics simulations, we used the computer program NAMD 2.8 [53] with CHARMM27 [54], in which the parameters used in the energy function are implemented for all atoms. For visualization and analysis of the simulation results, we used the graphics program VMD [55].

In each simulation, the structure was solvated in a water shell $20 \AA$ thick. The simulation was performed under normal temperature and pressure (NTP), and the temperature was raised slowly to $310 \mathrm{~K}$ in the first $62 \mathrm{ps}$. The total time of each simulation was $40 \mathrm{~ns}$.

\subsection{Visualization and Visual Inspection of Models}

The obtained models were visualized and inspected through the software UCSF ChimeraX [28] and PyMOL 2.0 [27].

\section{Conclusions}

By means of in silico analysis of primary sequences, molecular modeling, structural analysis, and molecular dynamics analysis, the present study showed that all the high and low-risk oncogenic E6 proteins analyzed have ID regions clustered at their $\mathrm{N}$ - and C-termini. However, high-risk HPV E6 proteins exhibit a much larger amount of disorder, especially at the C-terminus. The molecular modeling and simulation of molecular dynamics of the tertiary structures of HPV16 and HPV18 (high-risk), HPV6B and HPV11 (low-risk), and HPV1A (control) E6 proteins allowed the visualization of the structural variation at the termini of the proteins analyzed, evidencing the relationship between degree of oncogenicity and amount of ID at the termini. These results might implicate a direct relationship of the amount of ID to the degree of oncogenicity. These results are of vital importance and should be considered in future studies for the development of drugs based on molecular targets.

Supplementary Materials: Supplementary materials can be found at www.mdpi.com/1422-0067/19/1/198/s1.

Acknowledgments: This work was supported by Fundação de Amparo à Pesquisa do Estado de São Paulo (FAPESP) [process number 2013/21096-6, 2015/04606-6].

Author Contributions: The both authors contributed equally to this paper.

Conflicts of Interest: The authors declare no conflict of interest.

\section{Abbreviations}

HPV Human Papillomavirus

ID Intrinsic Disorder

RMSF Root Mean Square Fluctuations

$\mathrm{C} \alpha \quad$ Alpha Carbon

\section{References}

1. Tompa, P. Intrinsically unstructured proteins. Trends Biochem. Sci. 2002, 27, 527-533. [CrossRef]

2. Uversky, V.N. Natively unfolded proteins: A point where biology waits for physics. Protein Sci. 2002, 11, 739-756. [CrossRef] [PubMed] 
3. Uversky, V.N. A decade and a half of protein intrinsic disorder: Biology still waits for physics. Protein Sci. 2013, 22, 693-724. [CrossRef] [PubMed]

4. Wright, P.E.; Dyson, H.J. Intrinsically unstructured proteins: Re-assessing the protein structure-function paradigm. J. Mol. Biol. 1999, 293, 321-331. [CrossRef] [PubMed]

5. Xue, B.; Williams, R.W.; Oldfield, C.J.; Goh, G.K.-M.; Dunker, A.K.; Uversky, V.N. Viral disorder or disordered viruses: Do viral proteins possess unique features? Protein Pept. Lett. 2010, 17, 932-951. [CrossRef] [PubMed]

6. Berezovsky, I.N. The diversity of physical forces and mechanisms in intermolecular interactions. Phys. Biol. 2011, 8, 035002. [CrossRef] [PubMed]

7. Xue, B.; Williams, R.W.; Oldfield, C.J.; Dunker, A.K.; Uversky, V.N. Archaic chaos: Intrinsically disordered proteins in Archaea. BMC Syst. Biol. 2010, 4 (Suppl. 1), S1. [CrossRef] [PubMed]

8. Betiol, J.; Villa, L.L.; Sichero, L. Impact of HPV infection on the development of head and neck cancer. Braz. J. Med. Biol. Res. 2013, 46, 217-226. [CrossRef] [PubMed]

9. Van Doorslaer, K.; Bernard, H.-U.; Chen, Z.; de Villiers, E.-M.; zur Hausen, H.; Burk, R.D. Papillomaviruses: Evolution, Linnaean taxonomy and current nomenclature. Trends Microbiol. 2011, 19, 49-50. [CrossRef] [PubMed]

10. Rietz, A.; Petrov, D.P.; Bartolowits, M.; DeSmet, M.; Davisson, V.J.; Androphy, E.J. Molecular Probing of the HPV-16 E6 Protein Alpha Helix Binding Groove with Small Molecule Inhibitors. PLoS ONE 2016, 11, e0149845. [CrossRef] [PubMed]

11. Zanier, K.; Stutz, C.; Kintscher, S.; Reinz, E.; Sehr, P.; Bulkescher, J.; Hoppe-Seyler, K.; Travé, G.; Hoppe-Seyler, F. The E6AP binding pocket of the HPV16 E6 oncoprotein provides a docking site for a small inhibitory peptide unrelated to E6AP, indicating druggability of E6. PLoS ONE 2014, 9, e112514. [CrossRef] [PubMed]

12. Chung, C.H.; Gillison, M.L. Human papillomavirus in head and neck cancer: Its role in pathogenesis and clinical implications. Clin. Cancer Res. 2009, 15, 6758-6762. [CrossRef] [PubMed]

13. Shi, W.-J.; Liu, H.; Wu, D.; Tang, Z.-H.; Shen, Y.-C.; Guo, L. E6/E7 proteins are potential markers for the screening and diagnosis of cervical pre-cancerous lesions and cervical cancer in a Chinese population. Oncol. Lett. 2017, 14, 6251-6258. [CrossRef] [PubMed]

14. Ruttkay-Nedecky, B.; Jimenez Jimenez, A.M.; Nejdl, L.; Chudobova, D.; Gumulec, J.; Masarik, M.; Adam, V.; Kizek, R. Relevance of infection with human papillomavirus: The role of the p53 tumor suppressor protein and E6/E7 zinc finger proteins (Review). Int. J. Oncol. 2013, 43, 1754-1762. [CrossRef] [PubMed]

15. Schiffman, M.; Clifford, G.; Buonaguro, F.M. Classification of weakly carcinogenic human papillomavirus types: Addressing the limits of epidemiology at the borderline. Infect. Agents Cancer 2009, 4, 8. [CrossRef] [PubMed]

16. Wallace, N.A.; Galloway, D.A. Manipulation of cellular DNA damage repair machinery facilitates propagation of human papillomaviruses. Semin. Cancer Biol. 2014, 26, 30-42. [CrossRef] [PubMed]

17. Cornet, I.; Gheit, T.; Franceschi, S.; Vignat, J.; Burk, R.D.; Sylla, B.S.; Tommasino, M.; Clifford, G.M.; IARC HPV Variant Study Group. Human papillomavirus type 16 genetic variants: Phylogeny and classification based on E6 and LCR. J. Virol. 2012, 86, 6855-6861. [CrossRef] [PubMed]

18. Nicolau, N.; Giuliatti, S. Modeling and molecular dynamics of the intrinsically disordered e7 proteins from high- and low-risk types of human papillomavirus. J. Mol. Model. 2013, 19, 4025-4037. [CrossRef] [PubMed]

19. Uversky, V.N.; Roman, A.; Oldfield, C.J.; Dunker, A.K. Protein intrinsic disorder and human papillomaviruses: Increased amount of disorder in E6 and E7 oncoproteins from high-risk HPVs. J. Proteome Res. 2006, 5, 1829-1842. [CrossRef] [PubMed]

20. Iakoucheva, L.M.; Brown, C.J.; Lawson, J.D.; Obradović, Z.; Dunker, A.K. Intrinsic disorder in cell-signaling and cancer-associated proteins. J. Mol. Biol. 2002, 323, 573-584. [CrossRef]

21. Xue, B.; Dunbrack, R.L.; Williams, R.W.; Dunker, A.K.; Uversky, V.N. PONDR-FIT: A meta-predictor of intrinsically disordered amino acids. Biochim. Biophys. Acta 2010, 1804, 996-1010. [CrossRef] [PubMed]

22. Nominé, Y.; Masson, M.; Charbonnier, S.; Zanier, K.; Ristriani, T.; Deryckère, F.; Sibler, A.-P.; Desplancq, D.; Atkinson, R.A.; Weiss, E.; et al. Structural and functional analysis of E6 oncoprotein: Insights in the molecular pathways of human papillomavirus-mediated pathogenesis. Mol. Cell 2006, 21, 665-678. [CrossRef] [PubMed] 
23. Zanier, K.; Charbonnier, S.; Sidi, A.O.; McEwen, A.G.; Ferrario, M.G.; Poussin-Courmontagne, P.; Cura, V.; Brimer, N.; Babah, K.O.; Ansari, T.; et al. Structural basis for hijacking of cellular LxxLL motifs by papillomavirus E6 oncoproteins. Science 2013, 339, 694-698. [CrossRef] [PubMed]

24. Martinez-Zapien, D.; Ruiz, F.X.; Poirson, J.; Mitschler, A.; Ramirez, J.; Forster, A.; Cousido-Siah, A.; Masson, M.; Vande Pol, S.; Podjarny, A.; et al. Structure of the E6/E6AP/p53 complex required for HPV-mediated degradation of p53. Nature 2016, 529, 541-545. [CrossRef] [PubMed]

25. Janert, P.K. Gnuplot in Action: Understanding Data with Graphs; Manning Publications Co.: Greenwich, CT, USA, 2009; ISBN 978-1-933988-39-9.

26. Lowy, D.R.; Schiller, J.T. Reducing HPV-associated Cancer Globally. Cancer Prev. Res. (Phila.) 2012, 5, 18-23. [CrossRef] [PubMed]

27. Delano, W. The PyMOL Molecular Graphics System. Available online: http://www.pymol.org (accessed on 29 November 2017).

28. Goddard, T.D.; Huang, C.C.; Meng, E.C.; Pettersen, E.F.; Couch, G.S.; Morris, J.H.; Ferrin, T.E. UCSF ChimeraX: Meeting modern challenges in visualization and analysis. Protein Sci. 2017. [CrossRef] [PubMed]

29. Huang, F.; Oldfield, C.J.; Xue, B.; Hsu, W.-L.; Meng, J.; Liu, X.; Shen, L.; Romero, P.; Uversky, V.N.; Dunker, A. Improving protein order-disorder classification using charge-hydropathy plots. BMC Bioinform. 2014, 15 (Suppl. 17), S4. [CrossRef] [PubMed]

30. Radivojac, P.; Iakoucheva, L.M.; Oldfield, C.J.; Obradovic, Z.; Uversky, V.N.; Dunker, A.K. Intrinsic disorder and functional proteomics. Biophys. J. 2007, 92, 1439-1456. [CrossRef] [PubMed]

31. Terakawa, T.; Takada, S. p53 dynamics upon response element recognition explored by molecular simulations. Sci. Rep. 2015, 5, 17107. [CrossRef] [PubMed]

32. Heinen, A.; Kremer, D.; Göttle, P.; Kruse, F.; Hasse, B.; Lehmann, H.; Hartung, H.P.; Küry, P. The cyclindependent kinase inhibitor p57kip2 is a negative regulator of Schwann cell differentiation and in vitro myelination. Proc. Natl. Acad. Sci. USA 2008, 105, 8748-8753. [CrossRef] [PubMed]

33. Peng, Y.; Wang, L.; Qing, Y.; Li, C.; Ren, T.; Li, Q.; Li, M.; Zhang, S.; Shan, J.; Wang, G.; et al. Polymorphisms of BCL2 and BAX Genes Associate with Outcomes in Advanced Non-small cell lung cancer Patients treated with platinum-based Chemotherapy. Sci. Rep. 2015, 5, 17766. [CrossRef] [PubMed]

34. Paronetto, M.P. Ewing sarcoma protein: A key player in human cancer. Int. J. Cell Biol. 2013, $2013,642853$. [CrossRef] [PubMed]

35. Cino, E.A.; Karttunen, M.; Choy, W.-Y. Effects of molecular crowding on the dynamics of intrinsically disordered proteins. PLoS ONE 2012, 7, e49876. [CrossRef] [PubMed]

36. Marasco, D.; Scognamiglio, P.L. Identification of inhibitors of biological interactions involving intrinsically disordered proteins. Int. J. Mol. Sci. 2015, 16, 7394-7412. [CrossRef] [PubMed]

37. Pushker, R.; Mooney, C.; Davey, N.E.; Jacqué, J.-M.; Shields, D.C. Marked variability in the extent of protein disorder within and between viral families. PLoS ONE 2013, 8, e60724. [CrossRef] [PubMed]

38. Pelka, P.; Ablack, J.N.G.; Fonseca, G.J.; Yousef, A.F.; Mymryk, J.S. Intrinsic structural disorder in adenovirus E1A: A viral molecular hub linking multiple diverse processes. J. Virol. 2008, 82, 7252-7263. [CrossRef] [PubMed]

39. Yoshimatsu, Y.; Nakahara, T.; Tanaka, K.; Inagawa, Y.; Narisawa-Saito, M.; Yugawa, T.; Ohno, S.-I.; Fujita, M.; Nakagama, H.; Kiyono, T. Roles of the PDZ-binding motif of HPV 16 E6 protein in oncogenic transformation of human cervical keratinocytes. Cancer Sci. 2017, 108, 1303-1309. [CrossRef] [PubMed]

40. Spanos, W.C.; Hoover, A.; Harris, G.F.; Wu, S.; Strand, G.L.; Anderson, M.E.; Klingelhutz, A.J.; Hendriks, W.; Bossler, A.D.; Lee, J.H. The PDZ binding motif of human papillomavirus type 16 E6 induces PTPN13 loss, which allows anchorage-independent growth and synergizes with ras for invasive growth. J. Virol. 2008, 82, 2493-2500. [CrossRef] [PubMed]

41. Narisawa-Saito, M.; Yoshimatsu, Y.; Ohno, S.; Yugawa, T.; Egawa, N.; Fujita, M.; Hirohashi, S.; Kiyono, T. An in vitro multistep carcinogenesis model for human cervical cancer. Cancer Res. 2008, 68, 5699-5705. [CrossRef] [PubMed]

42. Obradovic, Z.; Peng, K.; Vucetic, S.; Radivojac, P.; Dunker, A.K. Exploiting heterogeneous sequence properties improves prediction of protein disorder. Proteins 2005, 61 (Suppl. 7), 176-182. [CrossRef] [PubMed]

43. Pons, J.-L.; Labesse, G. @TOME-2: A new pipeline for comparative modeling of protein-ligand complexes. Nucleic Acids Res. 2009, 37, W485-W491. [CrossRef] [PubMed] 
44. Sali, A. Comparative protein modeling by satisfaction of spatial restraints. Mol. Med. Today 1995, 1, $270-277$. [CrossRef] [PubMed]

45. Colovos, C.; Yeates, T.O. Verification of protein structures: Patterns of nonbonded atomic interactions. Protein Sci. 1993, 2, 1511-1519. [CrossRef] [PubMed]

46. Laskowski, R.A.; MacArthur, M.W.; Moss, D.S.; Thornton, J.M. PROCHECK: A program to check the stereochemical quality of protein structures. J. Appl. Crystallogr. 1993, 26, 283-291. [CrossRef]

47. Canutescu, A.A.; Dunbrack, R.L. Cyclic coordinate descent: A robotics algorithm for protein loop closure. Protein Sci. 2003, 12, 963-972. [CrossRef] [PubMed]

48. Rohl, C.A.; Strauss, C.E.M.; Misura, K.M.S.; Baker, D. Protein structure prediction using Rosetta. Meth. Enzymol. 2004, 383, 66-93. [CrossRef] [PubMed]

49. McGuffin, L.J. The ModFOLD server for the quality assessment of protein structural models. Bioinformatics 2008, 24, 586-587. [CrossRef] [PubMed]

50. Benkert, P.; Tosatto, S.C.E.; Schomburg, D. QMEAN: A comprehensive scoring function for model quality assessment. Proteins 2008, 71, 261-277. [CrossRef] [PubMed]

51. Krivov, G.G.; Shapovalov, M.V.; Dunbrack, R.L. Improved prediction of protein side-chain conformations with SCWRL4. Proteins 2009, 77, 778-795. [CrossRef] [PubMed]

52. Kyte, J.; Doolittle, R.F. A simple method for displaying the hydropathic character of a protein. J. Mol. Biol. 1982, 157, 105-132. [CrossRef]

53. Phillips, J.C.; Braun, R.; Wang, W.; Gumbart, J.; Tajkhorshid, E.; Villa, E.; Chipot, C.; Skeel, R.D.; Kalé, L.; Schulten, K. Scalable molecular dynamics with NAMD. J. Comput. Chem. 2005, 26, 1781-1802. [CrossRef] [PubMed]

54. MacKerell, A.D.; Bashford, D.; Bellott, M.; Dunbrack, R.L.; Evanseck, J.D.; Field, M.J.; Fischer, S.; Gao, J.; Guo, H.; Ha, S.; et al. All-atom empirical potential for molecular modeling and dynamics studies of proteins. J. Phys. Chem. B 1998, 102, 3586-3616. [CrossRef] [PubMed]

55. Humphrey, W.; Dalke, A.; Schulten, K. VMD: Visual molecular dynamics. J. Mol. Graph. 1996, 14, 33-38, 27-28. [CrossRef]

(C) 2018 by the authors. Licensee MDPI, Basel, Switzerland. This article is an open access article distributed under the terms and conditions of the Creative Commons Attribution (CC BY) license (http://creativecommons.org/licenses/by/4.0/). 